\title{
Novel biodegradable polymeric flocculants based on cationic polysaccharides
}

\author{
R. P. Singh ${ }^{1^{\star}}$, Sagar $\mathrm{Pal}^{2^{\star}}$, Sk. A. Ali ${ }^{3}$ \\ ${ }^{1}$ Emeritus Scientist, Indian Institute of Science Education and Research, Pune 411 021, India \\ ${ }^{2}$ Polymer Chemistry Laboratory, Department of Applied Chemistry, Indian School of Mines, Dhanbad, Dhanbad 826004, \\ Jharkhand, India \\ ${ }^{3}$ Research Scientist, ITC Limited, Bangalore 562157, India \\ "Corresponding author. E-mail: singh.prakash.ram@gmail.com (R.P. Singh), sagarpal1@hotmail.com (S. Pal); Tel: (+91) \\ 9420482405,3262235769 (S. Pal)
}

Received: 20 June 2013, Revised: 31 July 2013 and Accepted: 12 August 2013

\section{ABSTRACT}

Novel flocculants for wastewater and industrial effluents treatment have been developed in authors' laboratory based on modified polysaccharides. These flocculants have unique characteristics i.e. they are efficient with low dose usage like synthetic flocculants (e.g. polyacrylamide) and controlled biodegradable, shear resistant and inexpensive like polysaccharides. As contaminants have varying ionocity, various kinds of nonionic, anionic and cationic flocculants have been developed in authors' laboratory. The recent approaches on the removal of toxic materials, removal of colour and reduction of total pollutant content from various wastewaters using modified polysaccharides is becoming more important in the present frontier research, because of their worst impact towards environment as well as human health. The present article deals with the recent developments which took place in authors' laboratory on the synthesis of novel cationic flocculants based on modified polysaccharides derived from starch, amylose, amylopectin, chitosan, guar gum, glycogen, and tamarind kernel. The applications of these modified polysaccharides as flocculants for the treatment of various wastewaters including municipal sewage wastewater and as adsorbent for removal of reactive black dye from its aqueous solution have been discussed. The main objective of this article is to provide recent information about the most important features of these polymeric materials developed in authors' laboratory and to show the advantages gained from the use of flocculants based on cationic polysaccharides in wastewater treatment. Copyright $(0) 2014$ VBRI press.

Keywords: Biodegradable; cationic flocculants; flocculation; polysaccharides.

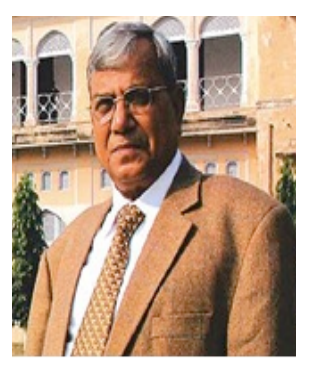

Ram Prakash Singh is working as Emeritus Scientist at Indian Institute of Science Education and Research, Pune. Prior to that he was the Vice-Chancellor of University of Lucknow, India. and Professor and Head of Materials Science Centre, Indian Institute of Technology, Kharagpur, India. His research interests include development of novel polymeric materials and their applications in the field of flocculation, drag reduction, rheology and agriculture. At present he is engaged in the scientific research on Polymer Solar Cells. He has more than 150 International publications in highly reputed journals along with 11 patents to his credit. Other than that he has also authored several review articles, books and book chapters. He is the recipient of several International and National Awards, including Prestigious P. J. Flory Award. He also holds memberships of many international and national scientific organizations and is a Fellow of the National Academy of Sciences, India and elected President of Indian Academy of Social Sciences.

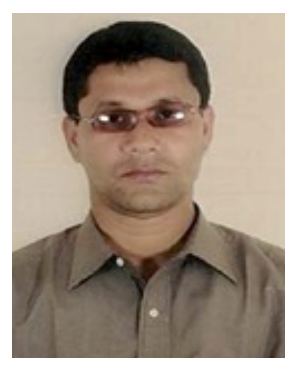

Sagar Pal is working as Associate Professor of Department of Applied Chemistry at Indian School of Mines, Dhanbad, India. Prior to that he was working as Lecturer in BIT, Mesra, Ranchi and Research Scientist (R \& D) at Hindustan Gum \& Chemicals Ltd., Bhiwani, Haryana, India. His research interests include development of polymeric hydrogels, nanogels, nanocomposites and their applications in various fields. He has been credited with 45 international publications in highly reputed journals, several book chapters and a patent. He is the recipient of DAAD Fellowship. Dr. Pal is working as Associate Professor of Department of Applied Chemistry at Indian School of Mines, Dhanbad, India. Prior to that he was working as Lecturer in BIT, Mesra, Ranchi and Research Scientist (R \& D) at Hindustan Gum \& Chemicals Ltd., Bhiwani, Haryana, India. His research interests include development of polymeric hydrogels, nanogels, nanocomposites and their applications in various fields. He has been credited with 45 international publications in highly reputed journals; several book chapters and a patent. He is the recipient of DAAD Fellowship. 


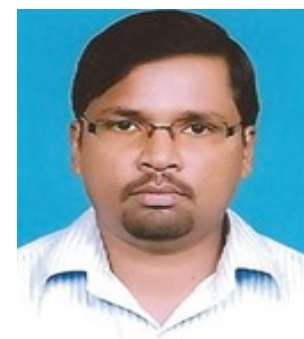

Sk. Akbar Ali is working as Research Scientist, ITC Limited, Bangalore, India. He obtained his Ph.D. in Polymer Science from Bundelkhand University, Jhansi, Uttar Pradesh, India and M. Tech. in Materials Science and Engineering from Indian Institute of Technology, Kharagpur, India. Earlier he worked at Piramal Enterprises, India and Hindustan Gum \& Chemicals Ltd. Bhiwani, Haryana as R \& D Scientist. His primary research areas include biopolymers and composite materials. He was the recipient of the best student award at Vidyasagar University (2001) and also a topper in his specialization at Indian Institute of Technology, Kharagpur, India. $\mathrm{He}$ is also associated with several scientific organizations.

\section{Introduction}

Water pollution because of toxic metals and organic compounds remain a serious environmental problem. Moreover, because of more stringent regulations, water pollution has become a major source of concern and a priority for most industrial sectors. Heavy metal ions, aromatic compounds, dyes are often found in the wastewater as a result of industrial discharge. They are the common contaminants in wastewater and many of them are known to be toxic or carcinogenic [1-2]. In addition, heavy metals are not biodegradable and tend to accumulate in living organisms causing various diseases and disorders [35]. Therefore, their presence in the environment, in particular in water, should be controlled. Removal of these contaminants from various wastewaters has received much attention in recent years [6]. Strict legislation on the discharge of these toxic contaminants makes it then necessary to develop various efficient technologies for the removal of pollutants from wastewater. Various traditional and advanced technologies and processes have been utilized for purification of wastewater, such as biological treatment [7-9], membrane processes [10, 11], advanced oxidation processes [12-14], adsorption procedure [15-16] and flocculation [17-19]. Amongst all the treatments proposed, flocculation is one of the most popular methods for the primary treatment of wastewater because it is now recognised as effective, efficient and economic method for water treatment application.

Flocculation is a process of removing organic and inorganic contaminants from wastewater and involves the aggregation of dispersed particles into larger flocs that can be separated from the water [20-22]. Flocculation is promoted by the addition of organic or inorganic chemicals, called flocculants. Inorganic flocculants react by the charge-neutralization principle and therefore, the large doses are required and a high amount of sludge is produced. Organic flocculants cause particle destabilization by effective bridging mechanisms [23]. Both natural and synthetic organic flocculants are available. Natural flocculants are mainly polysaccharides. The synthetic polymers are available in all three ionic forms, i.e. cationic, anionic and non-ionic. The natural flocculants have the advantage of low cost and biodegradability [24]. The biodegradability of natural polymeric flocculants is also a drawback, as it potentially reduces storage life and the flocculation performance [24]. On the other hand, synthetic polymers are highly efficient and can be tailored to the needs of a particular application [25]. However their biggest disadvantage is their shear degradability. It has been observed in authors' laboratory that by grafting/inserting synthetic polymer/cationic moiety onto polysaccharides, it is possible to develop efficient flocculant for the treatment of various wastewaters and industrial effluents [26-29]. As renewable raw materials, polysaccharides today play a major role as alternatives to fossil raw materials due to both of their generally non-toxic nature and the constantly rising global demand for energy and raw materials. The polysaccharides are large, organic molecules that occur in a variety of natural sources. Depending upon the source, these polysaccharides have many impurities and molecular distributions. However, by purification, grafting, hydrolysis, and cationization, useful products can be developed, which can be used as flocculating, drag reducing, percolation reducing, slow release, and viscosifying agents [30-34].

Earlier in authors' laboratory, various graft copolymers have been synthesised by grafting polyacrylamide chains onto amylopectin, amylose, carboxymethyl cellulose, chitosan, dextran, glycogen, guar gum, starch, xanthan gum etc. $[22,28,34-38]$. It was postulated by Singh that graft copolymers are more effective flocculants when compared with the linear polymers, because of the greater approachability of the dangling flexible polyacrylamide chains on rigid polysaccharide backbone to the contaminant particles in suspension [26]. Later on, it was found in authors' laboratory that glycogen-gpolyacrylamide (Gly-g-PAM) exhibits better flocculation characteristics in comparison with others [37]. This is because of the high molecular weight and highly branched nature of glycogen $[37,39]$. Most of these polyacrylamide grafted polysaccharides are mainly non-ionic in nature and are effective flocculants in the industrial effluents containing relatively low negativity contaminant particles. But for highly negatively charged colloidal particles, cationic polymers are more efficient [40].

Cationic high polymers are used as flocculating agents to remove finely divided solids from aqueous suspensions [41]. Highly charged cationic polymers such as polyquats, polyimines and polyamines are costly. Cationic polysaccharides, containing quaternary ammonium compounds represent a class of polymers that derive unique properties mainly from the density and distribution of positive charges along a macromolecular backbone. Like other polymers, cationic polysaccharides containing quaternary ammonium compounds find manifold applications. Therefore, they have been the subject of extensive investigations for several decades and still continue to be an active area of research. In view of authors' earlier findings, amylopectin (AP), amylose (AM), chitosan (Chi), glycogen (Gly), guar gum (GG), starch (St), and tamarind kernel polysaccharide (TKP) may be effective backbone polymers for creating reactive cationic moieties on them using a quaternary ammonium compound $\mathrm{N}$-3-chloro-2-hydroxypropyl trimethyl ammonium chloride (CHPTAC). Several mechanisms like 'charge neutralization' mechanism, 'bridging' displacement flocculation, etc. have been proposed to explain the destabilization of colloidal suspensions by cationic polymers. Taking into account that pollutants consisting of various negatively charged compounds such as thickeners, dispersing agents, anionic detergents, and inorganic 
preserving colloids etc., their intermolecular complexes with cationic polymers is expected to form. In view of the above explanations, cationic polysaccharide is expected to work as an efficient flocculant for the treatment of various wastewaters carrying substantial negative charges. This research account represents the development of various cationic polysaccharides and their applications as flocculants for treatment of wastewaters containing negatively charged suspended particles. The report is also focussed about the adsorption of reactive black dye from its aqueous solution using these cationic polysaccharides. The aim of the current research is to gain an improved understanding about the use of cationic polysaccharides as new generation of polymeric flocculants for treatment of various wastewaters.

Table 1. Synthesis details, intrinsic viscosity, molecular weight and radius of gyration of cationic polysaccharides.

\begin{tabular}{|c|c|c|c|c|c|c|c|c|}
\hline Polymer & $\begin{array}{c}\text { Amt. of } \\
\text { polysaccharid } \\
e(\mathrm{~mol})\end{array}$ & $\begin{array}{c}\text { Amt. of } \\
\text { CHPTAC } \\
\text { (mol) }\end{array}$ & $\begin{array}{l}\text { Vol. of } \\
\mathrm{NaOH} \\
(\mathrm{mol})\end{array}$ & $\begin{array}{l}\text { Temp. } \\
\left({ }^{\circ} \mathrm{C}\right)\end{array}$ & $\begin{array}{l}\text { Time } \\
\text { (hrs) }\end{array}$ & $\begin{array}{l}\text { Int. vis. } \\
\text { (dL/g) }\end{array}$ & $\begin{array}{l}\text { Mol. Wt. } \\
\text { (g/mol) }\end{array}$ & $\begin{array}{c}\text { Radius of } \\
\text { gyration } \\
(\mathrm{nm})\end{array}$ \\
\hline AM & -- & -- & -- & -- & -- & 1.7 & $4.64 \times 10^{4}$ & 6.35 \\
\hline CatAM & 0.0185 & 0.0106 & 0.015 & 50 & 18 & 9.3 & $6.89 \times 10^{4}$ & 9.18 \\
\hline AP & -- & -- & -- & -- & -- & 0.95 & $1.93 \times 10^{6}$ & 56.85 \\
\hline CatAP & 0.0185 & 0.0106 & 0.015 & 50 & 18 & 8.5 & $2.64 \times 10^{6}$ & 81.85 \\
\hline $\mathrm{CH}$ & -- & -- & -- & -- & -- & 0.32 & $4.3 \times 10^{3}$ & 9.70 \\
\hline Cat $\mathrm{CH}$ & 0.0092 & 0.0061 & 0.015 & 50 & 15 & 3.245 & $1.2 \times 10^{5}$ & 14.00 \\
\hline Gly & -- & -- & -- & -- & -- & 0.7 & $5.74 \times 10^{6}$ & 85.00 \\
\hline Cat Gly & 0.0092 & 0.0066 & 0.015 & 50 & 18 & 7.7 & $6.81 \times 10^{6}$ & 108.00 \\
\hline GG & -- & -- & -- & -- & -- & 8.2 & $1.16 \times 10^{5}$ & 31.60 \\
\hline CatGG & 0.0061 & 0.0066 & 0.015 & 50 & 18 & 15.6 & $6.60 \times 10^{5}$ & 44.00 \\
\hline TKP & -- & -- & -- & -- & -- & 2.8 & $6.05 \times 10^{5}$ & 61.30 \\
\hline Cat TKP & 0.0092 & 0.0053 & 0.010 & 50 & 18 & 11.3 & $6.12 \times 10^{6}$ & 76.82 \\
\hline St & -- & -- & -- & -- & -- & 1.2 & $1.06 \times 10^{5}$ & 10.10 \\
\hline Cat St & 0.0092 & 0.0066 & 0.015 & 50 & 18 & 8.7 & $4.32 \times 10^{5}$ & 21.50 \\
\hline
\end{tabular}

\section{Experimental}

\section{Materials}

Amylopectin, amylase, glycogen and chitosan were purchased from Sigma Chemicals Ltd., USA. Starch was supplied by E. Merck (India) Limited, Mumbai, India. Guar gum and tamarind kernel polysaccharide was gift sample from Hindustan Gum \& Chemicals Ltd., Bhiwani, Haryana. N-3-chloro-2-hydroxypropyl trimethyl ammonium chloride was procured from Lancaster Synthesis Company, England. Analytical grade of sodium hydroxide and hydrochloric acid was obtained from E. Merck (India) Limited, Mumbai, India. Isopropanol was supplied by S. D. Fine Chemicals, Mumbai, India. Silica was supplied by Jyoti Chemicals, Mumbai, India. Mn ore and Fe ore were gift samples from Joda Mines, Jharkhand, India.

\section{Synthesis}

The synthesis of cationic polysaccharides has been accomplished by inserting a cationic moiety $N$ - 3-chloro-2- hydroxypropyl trimethyl ammonium chloride (CHPTAC) in presence of sodium hydroxide. The reaction proceeds through $\mathrm{S}_{\mathrm{N}}{ }^{2}$ pathway as shown in Scheme 1. The optimization of synthesis parameters has been carried out [39, 42-48]. Table 1 provides the details of synthetic parameters for various cationic polysaccharides.

\section{Characterization}

Intrinsic viscosity measurement: Intrinsic viscosity measurements of the aqueous polymer solutions were carried out with an Ubbelohde viscometer (CS/S: 0.00386) at $25{ }^{0} \mathrm{C}$. The time of flow was measured at four $(0.1,0.05$, $0.025,0.0125 \mathrm{wt} \%$ ) different concentrations. The intrinsic viscosity (Table 1) for the polymer system at a given temperature $\left(25^{\circ} \mathrm{C}\right)$ was measured by the intercept of the plot of reduced viscosity $\left(\eta_{\mathrm{sp}} / \mathrm{C}\right)$ vs. $\mathrm{C}$ and inherent viscosity $\left(\ln \eta_{\text {rel }} / C\right)$ vs. C, when the linear experimental plot is extrapolated to zero concentration, or more precisely, to infinite dilution condition. CHN analysis: CHN analysis (Table 2) of various polysaccharides and cationic polysaccharides were carried out with an Elemental- Analyzer (Make - M/s Elementar, Germany; Model - Vario EL III).

Table 2. C, H, N analysis result.

\begin{tabular}{cccc}
\hline Polymer & \% C & \% $\mathbf{H}$ & \% N \\
\hline AM & 39.43 & 6.49 & 0.09 \\
CatAM & 39.58 & 6.68 & 3.24 \\
AP & 39.20 & 5.90 & 0.10 \\
CatAP & 39.40 & 6.62 & 4.94 \\
CH & 40.40 & 6.68 & 7.65 \\
Cat CH & 40.5 & 8.97 & 8.82 \\
Gly & 38.30 & 6.29 & 0.25 \\
Cat Gly & 38.42 & 6.21 & 5.02 \\
GG & 39.10 & 6.40 & 0.16 \\
Cat GG & 38.66 & 6.48 & 3.88 \\
TKP & 44.10 & 8.56 & 2.27 \\
Cat TKP & 39.00 & 8.60 & 6.22 \\
St & 39.31 & 6.36 & 0.12 \\
Cat St & 39.54 & 6.53 & 3.82 \\
\hline
\end{tabular}

Determination of weight average molecular weight and radius of gyration using SLS analysis: The weight average molecular weight and the radius of gyration of various polysaccharides and cationic polysaccharides were determined by static light scattering (SLS) technique with the help of DLS-7000 super dynamic spectrophotometer. The results are summarized in Table 1.

\section{Flocculation study}

Flocculation of simulated wastewater: The flocculation characteristics of polysaccharides, all synthesized cationic polysaccharides and that of commercially available cationic flocculant were investigated using Jar Test and Column Settling Test Method in various colloidal suspensions (Fe ore, $\mathrm{Mn}$ ore and silica suspensions).

\section{Flocculation of municipal sewage wastewater}

The flocculation characteristics of cationic polysaccharides were investigated using municipal sewage wastewater (collected from main sewage system plant of BIT-Mesra, 
Ranchi). The experiment was carried out in nine sets. In the control set, $400 \mathrm{~mL}$ of municipal sewage wastewater was stirred at a constant speed of $75 \mathrm{rpm}$ for 2 minutes followed by $25 \mathrm{rpm}$ for 5 minutes, left to settle for $15 \mathrm{~min}$, and the supernatant liquid was collected from the top layer. The remaining sets were treated in the same way, but in the presence of $9 \mathrm{ppm}$ of cationic amylopectin (Cat AP), cationic amylose (Cat AM), cationic chitosan (Cat Chi), cationic glycogen (Cat Gly), cationic guar gum (Cat GG), cationic starch (Cat $\mathrm{St}$ ), cationic tamarind kernel polysaccharide (Cat TKP), and Mag. LT 22 respectively. Determination of total solid (TS), total dissolved solid (TDS) and total suspended solid (TSS) was carried out gravimetrically. COD was determined by mixing of each 5 $\mathrm{ml}$ sample with $2 \mathrm{ml}$ digestion solution (sulphuric acid/mercuric sulfate/potassium dichromate/water) and 1.5 $\mathrm{ml}$ acid reagent (sulphuric acid + silver sulfate) followed by heating in a Digital Reactor Block 200 at $150{ }^{\circ} \mathrm{C}$ for $2 \mathrm{~h}$. The mixture was cooled and the COD value was measured with a HACH Portable spectrophotometer (Model $\mathrm{DR} / 2400)$.

\section{Adsorption study}

The adsorption experiments of reactive black dye solution were performed on a thermostated orbital shaker (Rivotek, Kolkata, India) with a shaking of $80 \mathrm{rpm}$ and maintained at $30{ }^{\circ} \mathrm{C}$ temperature for 1 hour in $100 \mathrm{~mL}$ conical flask. The experimental parameters such as solution $\mathrm{pH}$, initial concentration of metal ion, contact time, agitation speed, adsorbent dose and temperature were varied to optimized the adsorption condition. In all typical batch experiment 50 $\mathrm{mg}$ of the adsorbent (i.e. cationic polysaccharides and commercial cationic flocculant) was thoroughly mixed with $50 \mathrm{~mL}$ of $10 \mathrm{ppm}$ dye solution. After that the flask was shaken for the desired time, the suspension was filtered using $0.42 \mu \mathrm{m}$ filter paper and the concentration of dye in the adsorbed solution was analyzed using a UV-Visible spectrophotometer (Shimadzu, Japan) at a maximum absorbance wavelength $\left(\lambda_{\max }=542 \mathrm{~nm}\right)$. The percentage adsorption of dye was calculated using the following formula;

$\%$ Adsorption $=\frac{\mathrm{C}_{0}-\mathrm{C}_{\mathrm{e}}}{\mathrm{C}_{0}} \times 100$

where $\mathrm{C}_{0}$ is the initial concentration of dye solution ( $\mathrm{mg}$ $\left.\mathrm{L}^{-1}\right), \mathrm{C}_{\mathrm{e}}$ is the equilibrium concentration of dye solution $\left(\mathrm{mg} \mathrm{L}^{-1}\right)$. All the batch experiments were carried out in triplicate and the values reported here are the average of three readings.

\section{Results and discussion}

The flocculation efficiencies of various cationic polysaccharides and that of commercially available flocculant were determined in $0.25 \mathrm{wt} \%$ suspensions of silica (Fig. 1(a)), Fe-ore (Fig. 1(b)), and Mn ore (Fig. 1 (c)) suspensions. It is to be noted that cationic polysaccharides are better flocculants than that of base polysaccharide [42-48].

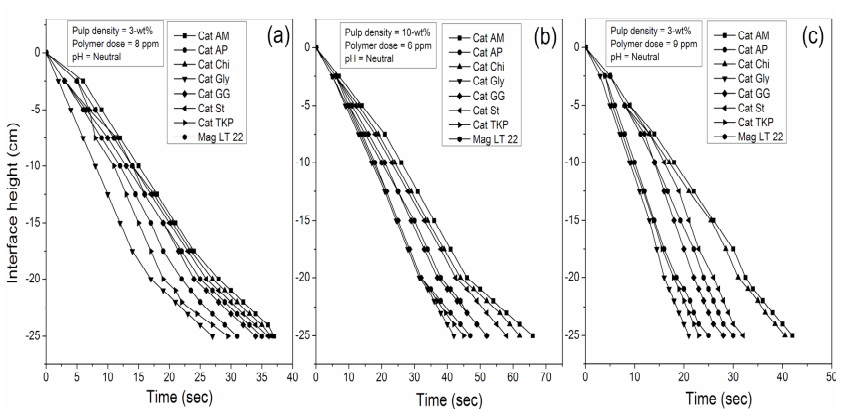

Fig. 1. Jar test result in (a) $0.25-w t \%$ silica, (b) $0.25-w t \%$ Fe-ore and (c) $0.25-\mathrm{wt} \% \mathrm{Mn}$ ore suspensions using various flocculants.

It is evident from Fig. 1 that cationised glycogen (Cat Gly) as flocculant dominates over all other cationic polysaccharides and commercial one in all suspensions. This is because of higher molecular weight, higher radius of gyration and highly branching nature of glycogen. It has already been established by Singh's Easy Approachability Model (both qualitatively and quantitatively) [26-27, 39, 49] that higher the radius of gyration (i.e. hydrodynamic volume) and branching nature of a polymer, greater is its flocculation efficiency, as higher is the branching in the base polysaccharide; the acrylamide / cationic moiety grafted/inserted onto polysaccharide will have more opportunity to form aggregate with the contaminants. When the grafted moiety or cationic moiety will be chemically loaded onto the highly branched polysaccharides, the modified polysaccharide has got easier accessibility to form aggregates of the contaminants, providing the best flocculation characteristics.

Table 3. Characteristics of various suspensions.

\begin{tabular}{cccc}
\hline $\begin{array}{c}\text { Suspension } \\
\text { Particle size } \\
(\mathbf{n m})\end{array}$ & $\begin{array}{c}\text { Specific gravity } \\
(\mathbf{g} / \mathbf{c c})\end{array}$ & $\begin{array}{c}\text { Zeta Potential } \\
(\mathbf{m V})\end{array}$ \\
\hline $\begin{array}{c}\text { pH: Neutral } \\
\text { Silica suspension }\end{array}$ & 102.3 & 3.10 & -53.5 \\
Fe-ore & 105.7 & 3.45 & -32.45 \\
suspension & & & -32.00 \\
Mn-ore & 86.90 & 2.50 & \\
suspension & & & \\
\hline
\end{tabular}

Although the bridging and charge neutralization mechanisms explain the effect of non-ionic and anionic polymers on the flocculation of colloidal particles, the effect of high charge cationics on negatively charged particles relates the poor experimental observation. For a system of high cationic charges [38] in anionic colloidal suspensions, the high interaction energy favours a flattened adsorbed configuration that reduces the formation of loops and trains [25], which can bridge the suspended particles. In such cases, surface charge particles cannot be neutralized individually with oppositely charged polymer segments. The charges on the polymer first form 'island' patches of charge, surrounded by areas of opposite charge. Particles with polyelectrolytes adsorbed in this "patchwise" manner can interact in such a way that oppositely charged areas of different particles come in contact giving rise to strong attraction. All the suspensions (Table 3) used here 
have high negatively charged colloidal particles and in this case it appears that the cationicity along with easy approachability dominates the performance of cationic glycogen.

The settling characteristics of various cationic polysaccharides and that of commercial flocculant were compared in silica (Fig. 2 (a)), Fe-ore (Fig. 2 (b)) and Mn ore suspensions (Fig. 2 (c)).

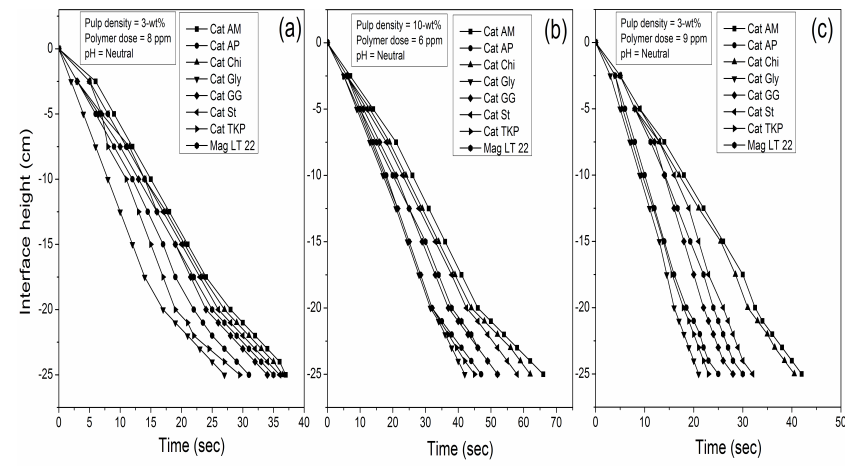

Fig. 2. Settling characteristics of (a) silica, (b) Fe-ore, and (c) Mn-ore suspensions using various flocculants.

Table 4. Settling velocities of various suspensions with addition of cationic polysaccharides and commercial flocculant.

\begin{tabular}{cccc}
\hline Polymer & $\begin{array}{c}\text { Settling velocity in } \\
\text { silica suspensions } \\
(\mathrm{cm} / \mathrm{sec})\end{array}$ & $\begin{array}{c}\text { Settling velocity in } \\
\text { Mn ore suspensions } \\
(\mathrm{cm} / \mathrm{sec})\end{array}$ & $\begin{array}{c}\text { Settling velocity in } \\
\text { iron ore suspensions } \\
(\mathrm{cm} / \mathrm{sec})\end{array}$ \\
\hline Cat AM & 0.71 & 0.61 & 0.43 \\
Cat AP & 0.90 & 1.08 & 0.62 \\
Cat Chi & 0.74 & 0.65 & 0.45 \\
Cat Gly & $\mathbf{1 . 1 7}$ & $\mathbf{1 . 2 5}$ & $\mathbf{0 . 6 4}$ \\
Cat GG & 0.83 & 0.90 & 0.54 \\
Cat St & 0.76 & 0.76 & 0.47 \\
Cat TKP & 1.05 & 1.12 & 0.63 \\
Mag LT 22 & 0.80 & 0.83 & 0.52 \\
\hline
\end{tabular}

From Fig. 2, it is obvious that cationic glycogen is the best flocculant even if when compared with a commercial cationic flocculant. The flocculation performance of a particular polymer could be correlated with the settling velocity. The higher the settling velocity of the floc containing contaminants, the greater will be its flocculation performance. From the settling curves, it has been observed that the fall of interface is linear for a considerable height before it becomes non-linear. This means that the rate of fall of the interface is constant initially, after which it gradually declines. Initial settling rate is calculated from the slope of the linear portion of the settling curves. In the present study, it was observed that satisfactory linearity was maintained for about $20 \mathrm{~cm}$ fall of the interface height in case of all suspensions. From figures, the settling velocities of various colloidal suspensions with the addition of different flocculants are calculated and the values are given in Table 4. Among all flocculants, the settling rate of silica, Fe ore and Mn-ore suspensions with addition of Cat Gly is found to be higher than that of others. Out of various cationic polysaccharides, cationic glycogen has high molecular weight and highly branched structure. With increase in branching and molecular weight and subsequent cationic loading on them, the approachability of the contaminants towards branched polysaccharides is enhanced and thereby enhancing the flocculation efficacy, which is reflected in the present experimental observation.
In addition, when compared with the commercial flocculant, because of higher molecular weight as well as higher radius of gyration, Cat Gly is showing better flocculation characteristics.

It is well known that municipal sewage wastewater constitutes an important part of the total wastewater from various sources. The amount of pollutants contained in the municipal sewage wastewater is around $28.6 \%$ of the average daily pollutant generation, which becomes a dominant factor. Proper treatment of municipal sewage wastewater becomes serious challenge in recent years. It is essential to treat municipal sewage wastewater before its discharge in order to elevate its water quality further to an appropriate level for possible agricultural and industrial reuse. Flocculation is an important industrial process for purification of municipal sewage wastewater for its reuse, as it can decrease the total pollutant content from the wastewater. Table 5 gives the results of analysis for treatment of municipal sewage wastewater using various flocculants. Here also it is evident that Cat Gly considerably reduces the overall pollutant load (i.e. TS, TSS, TDS, Turbidity, COD).

Table 5. Flocculating effect for treatment of municipal sewage wastewater.

\begin{tabular}{cccccc}
\hline Flocculant & $\begin{array}{c}\text { Turbidity } \\
(\mathbf{N T U})\end{array}$ & $\begin{array}{c}\text { TS } \\
(\mathbf{p p m})\end{array}$ & $\begin{array}{c}\text { TDS } \\
(\mathbf{p p m})\end{array}$ & $\begin{array}{c}\text { TSS } \\
(\mathbf{p p m})\end{array}$ & $\begin{array}{c}\text { COD } \\
(\mathbf{p p m})\end{array}$ \\
\hline Without flocculant & 64 & 630 & 280 & 350 & 540 \\
Cat AM & 32 & 325 & 225 & 100 & 310 \\
Cat AP & 8 & 165 & 130 & 35 & 195 \\
Cat Chi & 28 & 305 & 220 & 85 & 280 \\
Cat Gly & $\mathbf{4}$ & $\mathbf{1 5 0}$ & $\mathbf{1 2 5}$ & $\mathbf{2 5}$ & $\mathbf{1 7 5}$ \\
Cat GG & 13 & 230 & 170 & 60 & 255 \\
Cat St & 18 & 265 & 190 & 75 & 260 \\
Cat TKP & 7 & 160 & 130 & 30 & 185 \\
Mag LT 22 & 10 & 180 & 140 & 40 & 210 \\
\hline
\end{tabular}

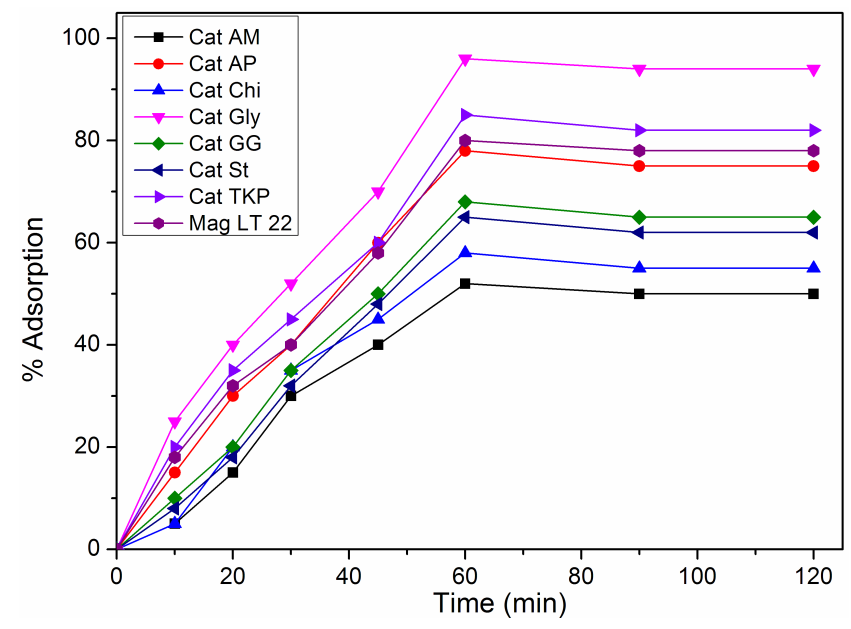

Fig. 3. \% Adsorption of reactive black dye from aqueous solution using various adsorbents.

Fig. 3 demonstrates competitive dye adsorption efficiency with time of various cationic polysaccharides in the optimized adsorption condition.

The mechanism behind the high adsorption using cationic polysaccharides is based on the fact that reactive black dye is anionic in nature. The anionic dye is electrostatically attracted by the cationic polymers. This reaction neutralizes the anionic charges of the dye and hence binds together with polymer and settles. When the 
quaternary ammonium groups present in polysaccharide backbone had neutralized the anionic charges completely, the $\%$ adsorption reached at maximum (i.e. the optimal adsorbent concentration). After which, destabilization took place because of electrostatic repulsion among the anions of dye, when the optimal adsorbent concentration exceeds. From the Fig. 3, it is evident that Cat Gly shows superior (96.2\%) dye adsorption capacity in comparison to others, even better than a commercial cationic flocculant. This is because of the higher radius of gyration, molecular weight and highly branch nature of Cat Gly. It is well known that with increase in the radius of gyration, the surface area of the polymer increases, which affects the adsorption efficacy. It is also to be noted that the adsorption efficiency of an adsorbent is highly dependent on physical and chemical characteristics as well as on the mass transfer rate. The mass transfer rate is highly dependent on the surface area. The maximum dye adsorption was observed for Cat Gly, because of its higher radius of gyration, which increases the mass transfer rate of anionic reactive dye in solution. Enhanced radius of gyration also increases the easy accessibility of the active sites of cationic glycogen.

\section{Conclusion}

On the basis of above discussions, it can be concluded that cationic polysaccharides are highly efficient flocculants for industrial effluent treatment, municipal sewage wastewater treatment and removal of colour from simulated reactive dye. Out of various cationic polysaccharides, cationic glycogen provides the best performance in various wastewaters. This is because of higher molecular weight, higher radius of gyration and highly branched nature of glycogen, which in turn will have better approachability to contaminants in the effluent in accordance to Singh's easy approachability and Brostow, Pal and Singh's flocculation model [49].

\section{Acknowledgements \\ Materials Science Centre, Indian Institute of Technology, Kharagpur, India; Birla Institute of Technology, Mesra, Ranchi, India; Indian School of Mines, Dhanbad, India; Indian Institute Science Education and Research, Pune, India; for supporting various aspects of present investigations are thankfully acknowledged. The collaboration with Prof. Witold Brostow, University of North Texas, USA and his group is also thankfully acknowledged.}

\section{Reference}

1. Kozlowski, C. A.; Walkowiak, W. Water Research, 2002, 36, 4870. DOI: $10.1016 / \mathrm{S} 0043-1354(02) 00216-6$

2. Crini, G. Prog. Polym. Sci. 2005, 30, 38 . DOI: $10.1016 /$ j.progpolymsci.2004.11.002

3. Schneegurt, M. A.; Jain, J. C.; Menicucci, J. A.; Brown, S. A.; Kemne,r K. M.; Garofalo, D. F.; Quallick, M. R.; Neal, C. R.; Kulpa, C. F. Environ Sci. Technol. 2001, 35, 3786. DOI: $\underline{10.1021 / \mathrm{es} 010766 \mathrm{e}}$

4. Naiya, T. K.; Bhattacharya, A. K.; Das, S. K.; J. Hazard. Mater. 2009, 170,252 DOI: $10.1016 / j$.jhazmat.2009.04.103

5. Chen, H.; Wang, A. J. Colloid Interface Sci. 2007, 307, 309. DOI: $10.1016 /$ j.jcis.2006.10.054

6. Uluozlu, O. D.; Sari, A.; Tuzen, M.; Soylak, M. Bioresour. Technol. 2008, 99, 2972.

DOI: $10.1016 /$ j.biortech.2007.06.052

7. Pearce, C. I.; Lloyd, J. R.; Guthrie, J. T.; Dyes Pigments. 2003, 58 , 179.

DOI: $10.1016 / \mathrm{S} 0143-7208(03) 00064-0$
8. McMullan, G.; Meehan, C.; Conneely, A.; Kirby, N.; Robinson, T.; Nigam, P. Appl. Microbiol. Biotechno. 2001, 56, 81 DOI: $10.1007 / \mathrm{s} 002530000587$

9. Fu, Y.; Viraraghavan, T. Bioresour. Techno, 2001, 79, 251. DOI: $10.1016 / \mathrm{S} 0960-8524(01) 00028-1$

10. Cassano, A.; Molinari, R.; Romano, M.; Drioli, E.; J. Mem. Sci. 2001, $181,111$.

DOI: $10.1016 / \mathrm{S} 0376-7388(00) 00399-9$

11. Goncharuk, V. V.; Kucheruk, D. D.; Kochkodan, V. M.; Badekha, V. P.; Desalination. 2002, 143, 45. DOI: $10.1016 / \mathrm{S} 0011-9164(02) 00220-5$

12. Lee, J. M.; Kim, M. S.; Hwang, B.; Bae, W.; Kim, B. W. Dyes Pig 2003, 56,59 . DOI: $10.1016 / \mathrm{S} 0143-7208(02) 00112-2$

13. Torrades, F.; Perez, M.; Mansilla, H. D.; Peral, J. Chemosphere. 2003, 53, 1211.

DOI: $10.1016 / \mathrm{S} 0045-6535(03) 00579-4$

14. Kurbus, T.; Sloker, Y. M.; Majcen, L. M. A.; Voncina, D. B. Dyes Pig. 2003, 58, 171 . DOI: $10.1016 / \mathrm{S} 0143-7208(03) 00054-8$

15. Singh, V.; Sharma, A. K.; Sanghi, R. J. Haz. Mat. 2009, 166, 327. DOI: $10.1016 /$ j.jhazmat.2008.11.026

16. Singh, V.; Singh, S. K.; Maurya, S.; Chem. Eng. J. 2010, 160, 129. DOI: $10.1016 /$ j.cej.2010.03.020

17. Sen, G.; Ghosh, S.; Jha, U.; Pal, S. Chem. Eng. J. 2011, 171, 495. DOI: $10.1016 /$ j.cej.2011.04.016

18. Pal, S.; Ghorai, S; Dash, M. K.; Ghosh, S.; Udayabhanu, G. J. Haz. Mat. 2011, 192, 1580.

DOI: $10.1016 /$ j.jhazmat.2011.06.083

19. Pal, S.; Sen, G.; Ghosh, S.; Singh, R. P. Carbohydrate Polymers. 2012, $87,336$. DOI: $10.1016 /$ j.carbpol.2011.07.052

20. Sen, G.; Singh, R. P.; Pal, S. J. Appl. Polym. Sci. 2010, 115, 63. DOI: $10.1002 / a p p .30596$

21. Ghosh, S.; Jha, U.; Pal, S.; Bioresource Tech. 2011, 102, 2137. DOI: $10.1016 / \mathrm{j}$. biortech.2010.08.105

22. Ali, S. K.; Pal, S.; Singh, R. P. J. Appl. Polym. Sci. 2010, 118, 2592. DOI: $10.1002 /$ app. 32580

23. Ghosh, S.; Sen, G.; Jha, U.; Pal, S. Bioresource Tech. 2011, 101, 9638.

DOI: $10.1016 / \mathrm{j}$. biortech.2010.07.058

24. Singh, R. P.; Pal, S. Krishnamoorthy, S.; Adhikary, P.; Ali, S. K. Pure Appl. Chem. 2009, 81, 525. DOI: $10.1351 / \mathrm{PAC}-\mathrm{CON}-08-08-17$

25. Singh, R. P.; Nayak, B. R.; Biswal, D. R.; Tripathy, T.; Banik, K. Mat. Res. Innov. 2003, 7, 331. DOI: $10.1007 / \mathrm{s} 10019-003-0273-\mathrm{Z}$

26. Singh, R. P., Advanced turbulent drag reducing and flocculating materials based on polysaccharides, Polymers and Other advanced Materials, Emerging technologies and business opportunities, (eds Prasad, P. N. , Mark, J. E., Fai, T. J., ), Plenum Press, New York, 1995, pp. 227-249.

27. Singh, R. P.; Karmakar, G. P.; Rath, S. K.; Karmakar, N. C.; Pandey, S. R.; Tripathy, T.; Panda, J.; Kannan, K.; Jain, S. K.; Lan, N. T. Polym. Engg. Sci. 2000, 40, 46 DOI: $10.1002 /$ pen. 11138

28. Rath, S. K.; Singh, R. P. J. Appl. Polym. Sci. 1997, 66, 1721. DOI: 10.1002/(SICI)1097-4628(19971128)66:9<1721::AIDAPP10>3.0.CO;2-Y

29. Pal, S.; Sen, G.; Karmakar, N. C.; Mal, D.; Singh, R. P. Carbohydrate Polymers, 2008, 74, 590 .

DOI: $10.1016 /$ j.carbpol.2008.04.007

30. Karmakar, N. C.; Rath, S. K.; Sastry, B. S.; Singh, R. P. J. Appl. Polym. Sci. 1998, 70, 2619

DOI: $\quad 10.1002 /(\mathrm{SICI}) 1097-4628(19981226) 70: 13<2619::$ AIDAPP7>3.0.CO;2-J

31. Sen, G.; Ghosh, S.; Kumar, R.; Pal, S. Carbohydrate Polym. 2009, 77,822 .

DOI: $10.1016 /$ j.carbpol.2009.03.007

32. Phukan, S.; Kumar, P.; Panda, J.; Nayak, B. R.; Tewari, K. N.; Singh, R. P. Agricultural Water Management. 2001, 47, 101. DOI: $\underline{10.1016 / \mathrm{S} 0378-3774(00) 00103-7}$

33. Stelter, M.; Brenn, G.; Yarin, A. L.; Singh, R. P.; Durst, F. J. Rheology. 2002, 46, 507. DOI: $10.1122 / 1.1445185$

34. Biswal D. R.; Singh R. P. Carbohydrate Polym. 2004, 57, 379. DOI: $\underline{10.1016 / j . c a r b p o l .2004 .04 .020}$ 
35. Krishnamoorthi S.; Mal D.; Singh R. P. Carbohydrate Polym. 2007, 69, 371-377.

DOI: $10.1016 /$ j.carbpol.2006.11.017

36. Adhikary, P.; Singh, R. P. J. Appl. Polym. Sci. 2004, 94, 1411. DOI: $10.1002 /$ app. 21040

37. P. Adhikary, P.; Tiwari, K. N.; Singh, R. P. J. Appl. Polym. Sci. 2007, 103, 773 .

DOI: $10.1002 /$ app. 25043

38. R. P. Singh, and K. Banik, High performance flocculants based on hydrolyzed and unhydrolyzed guar gum-g-polyacrylamide, Indian Patent Application No. 592/Cal/02 dated 18.10.2002.

39. Pal, S.; Mal, D.; Singh, R. P. Colloids and Surfaces A: Physicochem. Engg. Aspects. 2006, 289, 193.

DOI: $10.1016 /$ j.colsurfa.2006.04.034

40. Ellis, H. A.; Utah, S. I.; Ogunrinde, A.; Ogedengbe, M. O. Water Res. 1982, 16, 1433.

DOI: $10.1016 / 0043-1354(82) 90231-7$

41. Larsson, A.; Rasmusson, M. Carbohydrate Research. 1997, 304, 315 DOI: $10.1016 / \mathrm{S} 0008-6215(97) 00266-8$

42. Singh, R. P., Pal, S., Process for manufacture of cationic amylopectin and method of flocculation, Indian Patent No. -224777, 2008.

43. Pal, S.; Mal, D.; Singh, R. P. Carbohydrate polym. 2005, 59, 417. DOI: $10.1016 /$ j.carbpol.2004.06.047

44. Singh, R. P.; Pal, S.; Mal, D. Macromolecular Symposia. 2006, 242, 227.

DOI: $\underline{10.1002 / \text { masy.200651031 }}$

45. Pal, S.; Mal, D.; Singh, R. P. J. Appl. Polym. Sci. 2007, 105, 3240 DOI: $10.1002 /$ app. 26440

46. Pal, S.; Mal, D.; Singh, R. P. J. Appl. Polym. Sci. 2008, 108, 2674. DOI: $10.1002 /$ app. 27623

47. Brostow, W.; Lobland, H. E. H.; Pal, S.; Singh, R. P. Polym. Engg. Sci. 2008, 48, 1892.

DOI: $10.1002 /$ pen. 21064

48. Pal, S.; Ghosh, S.; Sen, G.; Jha, U.; Singh, R. P. Int. J. Biolog. Macromol., 2009, 45, 518 .

DOI: $10.1016 / j . i j b i o m a c .2009 .08 .004$

49. Brostow, W.; Pal, S.; Singh, R. P. Materials Lett. 2007, 61, 43814384 .

DOI: $10.1016 /$ j.matlet.2007.02.007

\section{Advanced Materials Letters}

\section{Publish your article in this journal}

ADVANCED MATERIALS Letters is an international journal published quarterly. The journal is intended to provide top-quality peer-reviewed research papers in the fascinating field of materials science particularly in the area of structure, synthesis and processing, characterization, advanced-state properties, and applications of materials. All articles are indexed on various databases including DOAJ and are available for download for free. The manuscript management system is completely electronic and has fast and fair peer-review process. The journal includes review articles, research articles, notes, letter to editor and short communications.

\section{JOURNAL}

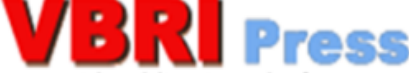

a rapid publication platform

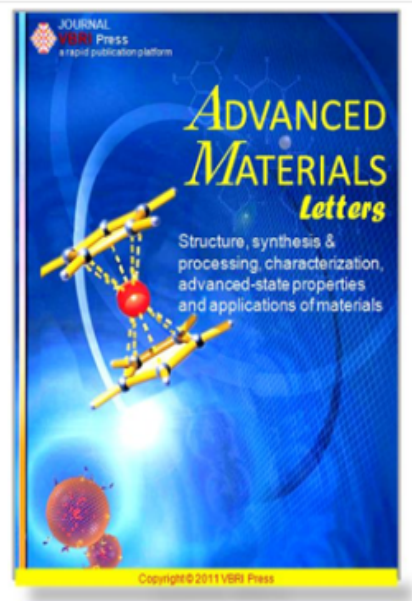

